ANUARIO DE ESTUDIOS MEDIEVALES

49/1, enero-junio de 2019, pp. 287-312

ISSN 0066-5061

https://doi.org/10.3989/aem.2019.49.1.11

\title{
ARMES, ARMADURES I BATALLES AL·LEGÒRIQUES EN ELS SERMONS DE VICENT FERRER*
}

\author{
ALLEGORICAL WEAPONS, ARMOUR AND BATTLES \\ IN THE SERMONS OF VINCENT FERRER
}

JOSEP YSERN

UNED

https://orcid.org/0000-0002-9767-6546

\begin{abstract}
Resum: L'expressió de la lluita contra el pecat, del combat contra el dimoni constitueix una de les isotopies més generals i esteses en la predicació vicentina. Aquest estudi intenta, d'una banda, descriure l'aprofitament de l'al·legoria de les armes del cristià, d'arrel paulina, per a l'expressió de tal eix semàntic; d'altra, il·lustra, amb mostres preses de sermons vicentins, la utilització de metàfores i al·legories de base militar per a l'expressió del conflicte amb el mal. Finalment, s'atura en l'estudi de la batalla campal contra el dimoni, inclosa en un sermó de Quaresma, situant aquesta en el context d'altres utilitzacions del mateix tòpic.
\end{abstract}

Paraules clau: Vicent Ferrer, predicació medieval, sermó, al·legoria, armadura, miles christianus, lluita.

Abstract: The expression of the fight against sin, the battle against the demon constitutes one of the most general and extended isotopies in the preaching of Vincent Ferrer. This paper attempts, on the one hand, to describe the exploitation of the allegory of the Christian's weapons, of Pauline origin, for the expression of such a semantic approach; on the other, it illustrates, with examples taken from Vincent Ferrer's sermons, the use of metaphors and military allegories for the expression of the conflict with evil. Finally, it concludes with the study of the pitched battle against the devil, included in a Lenten sermon, placing it in the context of other uses of the same topic or theme.

Keywords: Vincent Ferrer, medieval preaching, sermon, allegory, armour, miles christianus, fight.

\section{SUMARI}

1. La vida com a combat.-2. Una imatge paulina.-3. L'armadura paulina en dos sermons vicentins.- 4. Castells, ciutats i setges.- 5. Un sermó de quaresma totalitzador.- 6. Un punt de contrast: la batalla paròdica.- 7. Final.- 8. Bibliografia citada.

\section{LA VIDA COM A COMBAT ${ }^{1}$}

Al bell mig, al costat del pou, hi ha un foll. A banda i banda, l'església i la taverna són els edificis que emmarquen el bigarradíssim

\footnotetext{
${ }^{1}$ Abreviatures utilitzades: ApInv = Perarnau 1999; Gloss $a=$ Strabo 1852; MRet $=$ Lausberg 1966-1969; LBA = Ruiz 2009; Q = Ferrer 1973; S = Ferrer 1932-1988; SP = Ferrer 2006.

* El present estudi s'emmarca dins del projecte "La cultura literària medieval i moderna en la tradició manuscrita impresa" (VI), ref. FFI2017-83960-P.

Citation / Cómo citar este artículo: Ysern, Josep (2019), Armes, armadures i batalles al-legòriques en els sermons de Vicent Ferrer, "Anuario de Estudios Medievales” 49/1, pp. 287-312. https://doi.org/10.3989/aem.2019.49.1.11

Copyright: (C) 2019 CSIC. This is an open-access article distributed under the terms of the Creative Commons Attribution 4.0 International (CC BY 4.0) License.
} 
paisatge urbà amb què Pieter Brueghel, el vell, retrata una escena que bateja amb l'eloqüent títol De strijd tussen Carnival en Vasten o El combat entre Carnaval i Quaresma. De fet, el Carnaval -damunt una bota enormei la seva antagonista, la vella Quaresma -damunt una plataforma mòbil-, apareixen diametralment oposats a la part inferior del quadre, a punt de xocar. Un quadre recorregut per una línia que separa -o ajunta- dos mons irreconciliables. El conflicte entre el poder del cos -entre la carn- i l'esfera espiritual encara no ha esclatat, però n'és a punt. El reflecteix la pintura, així com també el teatre, la literatura. I, d'alguna manera, la predicació. Aquest darrer camp és el que ens interessa ara i ací, ja que el present estudi vol descriure la presència, articulació i desenvolupament del topos de les armes del cavaller i del conflicte bèl-lic en la predicació del dominic Vicent Ferrer. Primer, estudiarem la configuració primitiva, d'arrel paulina, d'aquest nucli semàntic, per a, tot seguit, il·lustrar-ne l'ús en la pràctica vicentina, sense menystenir ocasionalment, però, exemples per part d'altres autors.

La imatge de la vida com a combat és un dels tòpics més habituals de la literatura de caire moralitzador per tal com aquesta, normalment, prova d'atendre, entendre i resoldre els problemes amb què s'enfronta quotidianament el seu destinatari. Recordem com Francesc Eiximenis dedica el primer capítol de Lo crestià a explicar com Déus ha posat l'hom en aquest món "per batallar e per haver victòria de sos enemic" ", per tal que aconseguesca mèrit e glòria ${ }^{3}$. I rebla aquesta idea citant el versicle Militia est vita hominis super terram (Iob 7:1), que comenta de manera ben explícita:

la sua intenció [es refereix al sentit del versicle suara citat] és a dir que "tota la vida de l'hom és així com una bella cavalleria" d'un noble cavaller que s'ha de combatre ab son adversari per haver corona e gran glòria per la sua victòria.

Tot seguit, el teòleg franciscà conclou que, atès que tota la vida present de l'hom sia cavalleria, treball e misèria ningú no hauria de plànyerse en veure persones males, així com són mals regidors en lo món, o jutges corruptes, o defenedors de falsia, o lladres, adversaris de la cosa pública, estafadors o dins ses pròpies cases diverses contrarietats, sense oblidar fins i tot els conflictes íntims. Comptat i debatut si aitals coses no fossen, la present vida no fora camp de cavalleria ni temptació nostra, ni l'hom no fóra nat a treball ni l'home tindria la possibilitat d'obtenir mèrit ni victòria tan gran com

\footnotetext{
${ }^{2}$ Les cometes són meves.

${ }^{3}$ Eiximenis, Lo crestià, ed. Hauf 1983, p. 49.
} 
ara ha vencent los mals demunt dits e sobrant totes les adversitats e coses damunt dites ${ }^{4}$.

La vida com a conflicte, com a lloc de combat contra el mal, no és una imatge tampoc aliena a la predicació del dominic Vicent Ferrer. De fet, la documentarem, més avall, aprofitant el seu corpus sermonari -limitantnos, en principi, al d'expressió catalana-. L'abundor de mostres és tal que ens permet parlar de línia de força. Cal dir, però, que aquesta línia de força ve de lluny. Per això, primerament, convé descriure la nissaga, les arrels de la imatge que estudiarem per a, posteriorment, copsar la seva empremta en la producció sermonària de Ferrer.

\section{UNA IMATGE PAULINA}

Les epístoles de Pau de Tars, ensems amb el llibre dels Fets dels Apòstols, pertanyen als escrits fundacionals del cristianisme. Pau clou una d'aquestes cartes, la que tramet als efesis, amb uns mots que resulten ser claus quant al tema que ens ocupa ací. En acomiadar-se dels destinataris de la seva lletra, Pau els anima a vestir-se l'armadura de Déu per tal que puguin resistir els atacs del dimoni (Eph 6: 10). L'armadura els protegirà dels embats d'uns enemics que no són de carn i ossos, sinó que pertanyen a una altra realitat. En suma, doncs, els convé prendre l'armadura de Déu com a mitjà de defensa i de perfeccionament (Eph 6: 13). Acudim, però, al text original5:

De cetero confortamini in Domino et in potentia virtutis eius. Induite armaturam Dei, ut possitis stare adversus insidias Diaboli. Quia non est nobis colluctatio adversus sanguinem et carnem sed adversus principatus, adversus potestates, adversus mundi rectores tenebrarum harum, adversus spiritalia nequitiae in caelestibus. Propterea accipite armaturam Dei, ut possitis resistere in die malo et, omnibus perfectis, stare. State ergo succincti lumbos vestros in veritate et induti loricam iustitiae et calceati pedes in praepa-

\footnotetext{
${ }^{4}$ Eiximenis organitza els primers capítols del segon llibre de Lo crestià a l'entorn de la figura del "bataller", proposada com a model als seus lectors. Ho fa mantenint un paral-lelisme directe i conscient amb la manera d'actuar dels cavallers del moment. Així, per exemple, el segon capítol duu el títol de "Qui tracta lo primer acte del prous e savi bataller" i s'inicia recordant "què fa lo savi e prous cavaller quan sap que s'ha a combatre ab son adversari en lo camp a ell disputat", que marca la pauta del que haurà de fer el "feel cristià, com a noble bataller de la generosa cavalleria cristiana, per tal que no caja de l'alta dignitat de cristianisme" (Eiximenis, Lo crestià, ed. Hauf 1983, p. 51).

${ }^{5}$ Cito els textos bíblics, si no n'indico el contrari, segons la Nova Vulgata, editada pel Concili Vaticà II, accessible en xarxa (n'incloem la referència a la bibliografia final). Quan calgui traduir-los, es farà segons la traducció catalana interconfessional, inclosa a la bibliografia (Associació Bíblica de Catalunya, 1994).
} 
ratione evangelii pacis, in omnibus sumentes scutum fidei, in quo possitis omnia tela Maligni ignea exstinguere; et galeam salutis assumite et gladium Spiritus, quod est verbum Dei; per omnem orationem et obsecrationem orantes omni tempore in Spiritu, et in ipso vigilantes in omni instantia et obsecratione pro omnibus sanctis et pro me (Eph 6: 10-19).

Si seguim el text, veurem com, després d'haver animat els lectors de l'epístola a beneficiar-se de la protecció que confereix l'armadura de Crist, Pau enumera les parts de l'armadura, descrivint-ne, implícitament, l'ús 6 : cal posar-se el cinturó, però no un de qualsevol, sinó el de la veritat; cal revestir-se amb la cuirassa, però també es tracta d'una cuirassa peculiar: la de la justícia; cal anar ben calçats -i en aquest cas n'indica, més aviat, la utilitat del calcer: per a anunciar l'evangeli de la pau-; cal agafar l'escut de la fe-capaç d'apagar els dards encesos llançats pel maligne-, el casc de la salvació i l'espasa de l'Esperit -que és la paraula de Déu-. Per tant, podem veure com, en paral·lel a la funció d'aquests peces en el context de la lluita real, se'n defineix una altra, de figurada, corresponent al camp de lluita espiritual. L'eina retòrica que permet aquest salt és l'al·legoria, que, en aquest cas, actua per partida doble ${ }^{7}$. D'una banda, Pau al·legoritza el terme real de l'armadura ${ }^{8}$; però, tot seguit, hi haurà una llarga tradició d'exegesi del text paulí que, al seu torn, recorrerà també, en major o menor mesura, a l'al·legoria'.

${ }^{6}$ Aquesta imatge, implícitament, l'empra també Isaïes: "Indutus est iustitia ut lorica, et galea salutis in capite eius; indutus est vestimentis ultionis et operuit se zelo quasi pallio" (Is, 59: 17).

${ }^{7}$ Aquesta al·legorització múltiple és molt habitual amb els textos bíblics, com bé comenta Lausberg (MRet, §900), qui subratlla com, per damunt de les al·legories degudes a la voluntat autorial, la interpretació ha incrustat -és el terme exacte emprat per l'esmentat estudiós- allegories més àmplies. D'altra banda, quant a l'ús d'aquest recurs retòric en el context de la predicació, veg. Ferrer, Como una red, ed. Ysern 2015, pp. 52-54 (especialment la n. 48, amb bibliografia complementària d'interès).

${ }^{8}$ Cal dir que no és aquesta l'única volta en què Pau al-ludeix a la imatge de les "armes del cristiâ". En la segona carta als corintis, per exemple, els diu: "In carne enim ambulantes, non secundum carnem militamus -nam arma militiae nostrae non carnalia sed potentia Deo ad destructionem munitionum" (2 Cor 10: 3-4). També, en la carta als romans (Rom 13: 12), anima a bandejar les obres de les tenebres ("opera tenebrarum") i a vestir-se les armes de la llum ("arma lucis"); en la primera epístola als tessalonicencs anima de nou a posar-se la lloriga de la fe i la caritat i el casc de l'esperança de salvació (1 Tes 5: 8).

${ }^{9}$ No podem estendre'ns comentant aquesta tradició, però, per a estudiar-la, resulten molt útils les aportacions de Soukup 2007 i, molt particularment, la de Wang 1975. El primer estudia la metàfora de les Arma spiritualia en els sermons d'alguns predicadors representatius de la Reforma a Bohèmia, la qual cosa l'indueix a tractar aspectes de la tradició exegètica que, en part, poden ser extrapolats de l'àmbit referencial a què dedica el seu article. L'assaig de Wang, derivat de la seva tesi, estudia la imatge del miles christianus en els segles XVI i XVII, però tenint present la tradició medieval subjacent. El text paulí atès en aquests ratlles és estudiat molt detingudament -de fet, arma a arma- en la seva monografia (pp. 39-104). 
Precisament, amb la finalitat de llegir aquest text des d'una perspectiva medieval -abans d'arribar a la predicació vicentina, objecte d'aquest estudi-, recorrerem als comentaris de dos benedictins, Haymo i Ràban Maur ${ }^{10}$, que ens ajudaran a perfilar millor el sentit d'aquest topos, car llurs comentaris, d'alguna manera, conformen el sentit estàndard de la imatge de les armes del cristià.

Haymo dedica el capítol VI del seu comentari In epistola ad ephesios a glossar el lloc paulí que ens interessa ${ }^{11}$. El seu comentari avança ratlla a ratlla. En tractar el punt en què Pau anima a posar-se l'armadura de Déu $u t$ possitis stare adversus insidias Diaboli, Haymo es planteja què significa espiritualment aquest concepte d'armadura: spiritualiter quod debemus intelligere per armaturam Dei? ${ }^{12}$. I es respon identificant l'armadura amb Jesucrist mateix (ibidem): Dominum Jesum Christum cujus protectione defenduntur omnes electi. I Jesucrist és pres com a vestidura, subratlla remetent a l'epístola de Pau als Gàlates, amb el simple fet del baptisme: Quicumque enim in Christum baptizati estis, Christum induistis (Gal 3: 27). I vestir-se de Crist, en un següent pas interpretatiu, és tant com vestir-se de les virtuts pròpies de Crist. Per tant, l'afirmació paulina inicial és parafrasejada, a la fi, com Induite Dominum Jesum Christum, id est, omnes virtutes quas scitis in illo esse, in vobis assumite ${ }^{13}$, cosa que exemplifica detalladament. Així, doncs, aquesta armadura feta de les virtuts de Jesucrist és la que hauria de servir contra els atacs del dimoni, que s'esdevenen per malas suggestiones (...), per vitia carnis nostrae et incentiva malarum delectationum, contra els quals debemus nos viriliter pugnare, ne possimus superari.

Després d'explicar qui són aquests dimonis i com cal combatre' $1 \mathbf{s}^{14}$, Haymo analitza i comenta les diverses parts de l'armadura esmentades en l'epístola paulina ${ }^{15}$, cosa que té interès per les concrecions semàntiques i interpretatives a què arriba, com ara l'associació entre la idea de "posar-se el cinturó de la veritat" (el succinti lumbos vestros in veritate del text de Pau) i el control de la luxúria: Lumbos succingimus, cum luxuriam refrenamus ${ }^{16}$.

\footnotetext{
${ }^{10}$ Tots dos són aprofitats també per Soukup (2007, pp. 99-101). Respecte a Haymo, sembla que es tracta de Haymo d'Auxerre, benedictí mort cap al 865, bé que usarem la seva obra segons l'edició de Migne -inclosa a la bibliografia-, on s'atribueix a Haymo de Halberstadt, benedictí mort el 853 .

${ }^{11}$ Haymo 1881, cols. 731-734.

${ }^{12}$ Ibidem, col. 731.

${ }^{13}$ Aquesta mateixa afirmació -també amb la referència al baptisme-, ja l'aprofita Haymo en comentar l'epístola paulina als romans (Ibidem, col.485).

${ }^{14}$ Ibidem, col. 732.

${ }^{15}$ Ibidem, cols. 733-734.

${ }^{16}$ Ibidem, col. 733 .
} 
El lligam amb la idea de "veritat" que apareix en el text paulí s'hi afegeix, de manera un tant forçada, tot seguit (ibidem): et hoc in veritate facite, non in mendacio neque per hypocrisim neque ut laudem hominum capiatis ${ }^{17}$. La lorica és associada amb la justícia per tal com es compon de múltiples peces, ita justitia multis virtutibus constat, alhora que serveix també per a controlar el cos: així com la lloriga enforteix el pit, protegeix el ventre i les cuixes, la justícia superfluas cogitationes quae in pectore versari solent, repellit, ingluviem ventris stringit, luxuriam quoque comprimit (ibidem). El calcer és explicat doblement. D'una banda, mitjançant la idea de protecció: així com qui va calçat evita el perill de les serpents o el destorb de les espines, l'usuari de la versió espiritual del calcer evitarà diabolum serpentem antiquum, spinas quoque, id est, punctiones passionum; d'altra banda, al-ludint al material del qual es fa: per calceamenta quae ex mortis animalibus fiunt, debemus intelligere dicta et exempla sanctorum patrum praecedentium. Potser -deixant de banda, ara, la resta d'elements per no ser massa prolix-, el casc -galea salutis en la carta de l'apòstol- és la part de l'armadura tractada més detalladament. El casc, posat al cap, protegeix tots els sentits del cos: la vista, perquè protegeix els ulls; l'oïda, perquè tapa les orelles; el gust o l'olfacte, perquè cobreix la boca o el nas. Per tant, què pot ser el casc, que omnes sensus corporis protegit ${ }^{18}$. La resposta és clara (ibidem): Dominum Jesum Christum et proteccionem illius.

Ràban Maur, en la seva Expositio in epistolam ad Ephesios, segueix un procediment de comentari del text de Pau semblant al de Haymo i sovint arriba a conclusions similars. Per exemple, també afirma que vestir-se l'armadura de Jesucrist és quasi dixerit: Induite Dominum Iesum Christum $^{19}$, idea que subratlla, poc després, dient que qui vagi així vestit potens erit contra universas insidias diaboli repugnare. Igualment, insisteix en el paral·lelisme entre el cos i l'ànima, de manera que tots els membres del cos han de tenir un equivalent espiritual-Quod juxta membra carnis et corporis omnia membra animae in Scripturis vocentur nulli dubium est ${ }^{20}-\mathrm{i}$ el veurem coincidir amb

${ }^{17}$ Wang (1975, pp. 40-45) analitza el procés pel qual el "cingulum militiae" originari, un símbol d'autoritat, esdevé finalment expressió de la castedat en l'àmbit monàstic. En el procés intervé l'ús del "cingulum" com a part de la indumentària sacerdotal. En qualsevol cas, el fet que el sacerdot o el monjo es defineixi com a "miles christianus" implica que la vestidura sacerdotal, d'arrel veterotestamentària, sigui reinterpretada segons la imatgeria pròpia de la idea de "milícia": "Sobald der Priester oder Mönch als miles christianus sich begreift, er legt seine seit alttestamentlicher Zeit tradierte Bekleidung und deren Teile unter Verwendung der 'militia'-Bildichkeit aus" (Wang 1975, p. 42). Sobre aquest procés de militarització de la simbologia sacerdotal i les seves consequiències són molt il·lustratives les paraules de Hauf 1990, pp. 269-274.

${ }^{18}$ Haymo 1881, col. 734.

${ }^{19}$ Maurus 1852, col. 466.

${ }^{20}$ Ibidem, col. 472. 
Haymo en parlar del "cinturó de la veritat", quan diu: videtur nobis accinxisse lumbos suos qui neququam uxori debitum reddit, nec servit libidini, sed imitatur ingenitum Deum, generationis negotiis non ministrans ${ }^{21}$. Tanmateix, a l'hora de parlar del calçat, no recorre tant a la idea dels perills del camí, sinó que, recordant com a peu ingredimur in eo qui dicit "Ego sum via", descriu la preparació per a llançar-se a caminar, tot seguint el llibre de l'Èxode (12: 11): renes vestros accingetis, calceamenta habebitis in pedibus, tenentes baculos in manibus, et comedetis festinanter.

Heus ací només dues mostres, però il·lustren perfectament la línia interpretativa que prendrà Vicent Ferrer, com veurem tot seguit, en els sermons que desenvolupen l'al-ludida imatge paulina, centre d'atenció del següent punt.

\section{L'ARMADURA PAULINA EN DOS SERMONS VICENTINS}

Ferrer aprofita l'al'legoria paulina de l'armadura en dos sermons: un sota el tema Accipite armaturam Dei (S IV, pp. 261-262); l'altre, sota el tema Induite vos armaturam Dei (S IV, pp. 263-268) ${ }^{22}$. De fet, ja en el primer adverteix Ferrer que té intenció de dedicar-ne dos a reflexionar sobre per què sent Pau nos amoneste axí com si ell fos hun gran bataller, e que.ns armem per tal que siam forts en la batalla (p. 261), fins i tot centrant cadascun d'ells en una qüestió concreta, com explica de bon començament (p. 261):

E sapiau que qui desarmat serà atrobat, serà vençut. E per ben declarar aquesta matèria, ací vénen dues qüestions, e de la una serà huy lo sermó, e de la segona serà lo de demà. E la primera qüestió serà contra qui nos devem armar; e la segona serà contra quinyes armes nos devem subvenir.

${ }^{21}$ Ibidem, col. 473.

${ }^{22}$ Em limito al corpus sermonari vicentí en català. Perarnau documenta dos desenvolupaments del "Accipite..." (cf. ApInv, núms. 12 i 13) i altres dos del tema "Induite..." (cf. ApInv, núms. 455 i 456). Els dos sermons a què em referiré ací han estat indexats en ApInv 13 i 456, respectivament. D'altra banda, tots dos temes estan inclosos en SP, en les fitxes núms. 348 (per al tema "Induite...") i 349 (per al tema "Accipite..."), si bé els desenvolupaments previstos no corresponen a la realitat dels dos testimonis concrets ací tractats. La fitxa 348 preveu per al seu tema el desenvolupament que ací trobarem en el sermó dedicat a "Accipite...", mentre que la 349 planteja una divisio que, tanmateix, trobarem en el sermó centrat en "Induite...". Aquesta constatació té interès per tal com palesa la flexibilitat de tots els esquemes previstos, alhora que fa veure la utilitat de conjuminar la perspectiva del catàleg -fonamental- de Perarnau (ApInv) amb la del cedulari de Perusa (SP). Per no pecar de prolixitat, però, no entrarem ací en més consideracions comparatives entre els textos inclosos en les referències esmentades. 
Per a desenvolupar el primer sermó, dedicat a definir contra qui cal lluitar, distingirà una tríada d'objectius: segons el lloc, segons els enemics i segons el premi esperat ${ }^{23}$. El "lloc" és identificat amb aquest món i es caracteritza per ser un espai intermedi entre l'espai superior -la glòria celestiali l'inferior -l'infern-. Els qui viuen en la glòria no cal que s'armin, car los dimonis no s'i poden acostar, e totstemps han pau ${ }^{24}$ (p. 261). Tanmateix, a nosaltres, qui estam enmig, parle lo tema, e nosaltres qui havem lo franch, podem fer bé e mal, e per [ço] convé que.ns armem (p. 262).

D'altra banda, els enemics contra els quals es batalla són els dimonis, essencialment invisibles. La major part d'ells estan en l'ayre, sinó uns pochs que n’ha ací en lo món, e altres pochs en infern (p. 262). Insisteix que són l'enemic fonamental, tot recorrent al text de la carta als efesis on Pau recorda que la lluita no és adversus carnem et sanguinem (Eph 6: 12), aspecte en el qual s'insisteix molt en SP, núm. $348^{25}$. Tota aquesta lluita, evidentment, té com a objectiu final -lo lloguer que $n$ speram - aconseguir la glòria del paradís (p. 262), idea que, en SP, se subratlla amb una citació d'una altra carta de Pau: Collabora sicut bonus miles Christi Iesu (2 Tim 2: 3).

Serà en el sermó sobre el tema Induite vos armaturam Dei (S IV, pp. 263-268) on trobarem una bastida retòrica basada en la descripció -al·legòrica- de les diverses parts de l'armadura, ja que Sent Pau (...) ara nos avise quinyes armes devem pendre contra los enemichs (p. 263). Després, inclou el fragment de la citació paulina vista adés, on s'enumeren les parts de l'armadura $^{26}$, que tot seguit interpreta (ibidem):

E diu que'ns armem, primo, de castimònia integral; secundo, de penitència virtual; tercio, de paciència general; $4^{\circ}$, de credència divinal; $V^{o}$, de confidència supernal; sexto, de oració devotal.

\footnotetext{
${ }^{23}$ Aplica així el que ja es preveia en SP, núm. 348: "contra que debemus armari: Locum in quo sumus; Inimicos quos habemus; Premium quod spectamus".

${ }^{24}$ Autoritza aquesta afirmació amb una citació -"Erit pulcritudo pacis (...) in sempiternum"que sembla ser factícia a partir del llibre d'Isaïes (32: 17-18) -segons la informació que dona la fitxa de SP, malgrat que en l'edició de base se la localitza en l'Eclesiàstic-. En qualsevol cas, contrasta el versicle bíblic amb la seva experiència del món coetani (pp. 261-262): "No és axî́ en aquest món, que quan los hòmens d'armes han pau, veus que no han bellesa, car pus que no han guerra uns ab altres, fan sutzures ab dones, e per ço no han bellesa".

25 "Inimici nostri, scilicet demones, sunt potentissimi et nos infirmi; sunt astutissimi et nos inexperti; sunt invisibiles et nos patentes". Tot seguit introdueix la mateixa citació paulina suara esmentada, a partir de la qual aïlla les "bella demonum contra nos": "Primum in vita", cosa que lliga al paulí "Adversus principes et potestates"; "secundum, in morte", cosa que relaciona amb el fragment "adversus mundi rectores tenebrarum harum", de la carta als efesis; i, "tertium post mortem in aere", és a dir, "Contra spiritualia nequitiae in celestibus".

${ }^{26}$ Concretament: "State ergo succincti lumbos vestros in veritate (...) quod est verbum Dei" (Eph 6: 14-17).
} 
A partir d'ací, l'orador ha d'anar justificant la divisió plantejada. Comença per l'aplicació de la idea de castedat al "cinyell" amb què relaciona el versicle paulí State ergo succincti lumbos vestros in veritate et induti loricam iustitiae (Eph 6: 14) ${ }^{27}$. S'estén més, però, en la identificació de la lloriga -que defineix com "cota de malla" 28 amb la penitència, per arribar després a lligar aquesta amb la justícia, esmentada en el text paulí. Estableix diversos paral-lelismes entre la cota de malla i la penitència: per exemple, la cota de malla és feta de moltes anelletes (ibidem), com també la penitència és de moltes anelletes, de moltes obres e de molts dolors de peccats e de moltes làgrimes e de moltes confessions (ibidem); a més, si de la cota tirau una anelleta, veus (...) que tota.s desfarà (ibidem), fet que també troba en la penitència, pel seu lligam amb la gràcia de Déu; la cota és dura, com també ho és la penitència; i, sobretot, la cota de malla cobre davant e derrere e als costats (ibidem), com també fa la penitència, ja que aquesta serveix per a perdonar els pecats ja fets (relacionats amb la idea de "darrere"), prepara per a enfrontar-se als futurs (associats a la idea de "davant"), protegeix el costat esquerre (que el predicador associa al fet d'evitar la damnació) i el dret (la qual cosa assegura la salvació). Explicat això, fa el salt interpretatiu que ha de vincular la penitència a la justícia, per servar fidelitat al text paulí: qui fa penitència no és alre sinó que fa justícia de si matex (ibidem), idea que aclareix al·ludint al judici personal post mortem $^{29}$.

La relació del calcer amb la "paciència general" es fa escenificant davant el públic com camina qui va ben calçat ${ }^{30}$ : quan la persona va descalça, si una pedreta li punxa, tantost crida "Aay!"; mas si va bé calçada, no. Per això, qui va descalç tantost que li dien una injúria, tantost se sent e crida, mentre que qui va ben calçat no se'n sent, ans diu suaument: "Déus vos ó perdó”. Mitjançant aquesta associació i passant per una citació de l'Èxode, en la qual s'exhorta el poble d'Israel a estar ben calçat i tenir un bastó a la mà per a iniciar la fugida d'Egipte (Ex 12: 11) -citació ja prevista en SP, núm. 349-,

${ }^{27}$ Cf. supra n. 17. Recordeu que el cíngol sacerdotal representa la castedat. De més a més, aquesta interpretació ja l'havia recollida la Glossa, que comenta "succinti lumbos vestros" dient: "Id est carnales concupiscentias cingulo castitatis frenantes non simulatorie, sed in veritate, vel per charitatem" (Glossa, col.600).

${ }^{28} \mathrm{~S}$ IV, p. 264.

${ }^{29} \mathrm{Cal}$ dir que la Glossa planteja la mateixa associació que, fidel a la font paulina, fa ací Ferrer entre la justícia i la lloriga, però sense passar per la idea de penitència -modificació vicentina-. També la justícia es compon de moltes anelles -"lorica multis circulis contexitur" (Glossa, col. 600)-, que en aquest cas són les virtuts. Igualment, la justícia cobreix tot el cos, com la lloriga. Per això "ita justitia superfluas cogitationes quae in pectore versari solent repellit (...) luxuriam quoque opprimit" (ibidem).

${ }^{30}$ S IV, p. 265. 
el calcer acaba identificat amb la creu per tal com aquesta representa la paciència de Jesucrist davant un sofriment incomportable. Val a dir que, de manera concisa, fra Vicent intenta despertar en el seu oïdor compassió pels dolors de Crist durant el seu suplici ${ }^{31}$ :

pren aquests bastons en lo teu cor, pensa quan lo clavaven los jueus. (...) Ara pren tu aquests bastons en la memòria de la tua ànima, de la passió de Jesuchrist e de les dolors que sostenie en la creu; e si-u fas, serà pacient, e seràs calçat, e no't sentiràs de les dolors e injúries.

L'escut, tanmateix, per la seva forma triangular, s'associa amb la Trinitat, cosa que justifica el seu lligam amb la "credència divinal", reforçat amb un desenvolupament al-legòric basat en el seu ús: com que l'escut "se porte en lo braç esquerre", el costat esquerre s'associa a la vida terrenal i, en aquest món, "jatsesie que hom a huyll no veja les veritats de la fe, mas creem-ho" 32 .

Una cosa, però, és la "credència" i, una altra, la "confidència supernal", que s'associa al casc i que, segons Ferrer, és no confiar [en] ${ }^{33}$ res d'aquest món, ni en or ni en argent, car tot ó has a lexar; mas posar la sua sperança en Déu (...) E per ço posau tota la sperança vostra en lo nom de Jhesús (ibidem). Esperonat per aquesta idea, al·legoritza el tradicional monograma amb què se sol representar Jesucrist:

E veus $I H S$ en scriptura. Què signifique la $H$ ? Signifique la divinitat e la humanitat, e lo títol signifique la corona. (...) Vet ací la $I$, que és chiqua. La $S$, retorcillada, és lo ladre de la esquerra, qui fon retort, e los punts chichs deçà e dellà signifiquen la verge Maria e sent Johan ${ }^{34}$.

Tinguem present l'enorme valor que dona Ferrer al nom de Jesús -i a la creu- com a recurs defensiu dels creients, de caràcter que a voltes semblaria quasi màgic ${ }^{35}$, car, de fet, en parla com a remei substitutori de les visites a endevins o fetillers.

\footnotetext{
${ }^{31}$ A voltes Ferrer, en la seva predicació, sembla reforçar actituds i pautes d'oració i vida que habitualment se solen relacionar més aviat amb l'espiritualitat franciscana. Vegeu al respecte Ferrer, Como una red, ed. Ysern 2015, p. 92, n. 99 i p. 95, n. 103.

${ }^{32}$ S IV, p. 266.

${ }^{33}$ Correcció meva pel sentit.

${ }^{34} \mathrm{~S}$ IV, pp. 266-267.

${ }^{35}$ Vegeu, sobre aquest aspecte, Ferrer, Como una red, ed. Ysern 2015, 109-110.
} 
La identificació de l'oració amb una espasa es justifica, prèvia resolució d'un possible problema gramatical ${ }^{36}$, perquè oració devota és coltell tallant de dues parts, la una als dimonis, e l'altra als hòmens ${ }^{37}$, descripció que sembla ser una adaptació del que diu la Glossa (col. 600) sobre aquest mateix punt:

Verbum Dei est gladius bis acutus, docens de temporalibus et aeternis. (...) Quod enim temporaliter nobis promissum est, ad unam partem gladii; quod vero in sempiternum ad aliam partem gladii pertinet.

Ara bé, la idea de l'al-legoria, d'arrel paulina, centrada en l'armadura no exhaureix el tema de la vida com a conflicte, com a combat contra el pecat a fi d'arribar a la glòria, premi després de la mort. La conflictivitat que batega en aquest projecte ètic s'expressa també a través d'altres mitjans, com veurem tot seguit.

\section{CASTELls, CIUTATS I SETGES}

En el sermó dedicat al tema Beati mortui qui in Domino moriuntur ${ }^{38}$, fra Vicent toca el tema de les condicions de les ànimes que passen de aquesta present vida en l'altra (S I, p. 67), centrant-se concretament en les maneres que hi ha "de bé a morir" (p. 68), és a dir, de bona mort. La segona manera de ben morir és de algunes persones que oren per Déu virtuosament (p. 70), on tenen cabuda:

Los màrtirs, qui per mantenir la honor de Déu, e per servar los seus manaments, o per la fe, quan a tals persones los hix l'ànima del cors, tantost va a paraís sens purgatori; car la mort de aquell turment $\mathrm{ab}$ què $1 \mathrm{~s}$ maten, los va[1] ${ }^{39}$ per purgatori, per gran peccador que sia.

I és precisament, just després d'aquesta explicació, on el predicador activa el primer tòpic que hem vist més amunt (pp. 70-71):

\footnotetext{
${ }^{36}$ Efectivament, l'orador preveu que algú pugui posar ets i uts al fet que el versicle paulí diu "quod est verbum Dei", tot i el gènere masculi de l'antecedent ("gladius"). Qui cregués això "raurie-s' ho" (S IV, p. 267). Llavors s'exclama fra Vicent: "Oo, qui·t tallave la mà! Car lo 'quod' non refertur ad rem, sed ad vocem!" (ibidem).

${ }^{37}$ S IV, p. 267.

${ }^{38} \mathrm{Hi}$ ha tres sermons vicentins sobre aquest tema, convenientment catalogats per Perarnau 1999 ( $c f$. ApInv pp. 501-502, núms. 59, 60, 61). El que comentem ací és l'inclòs en S I, pp. 67-75, corresponent al núm. 60 d'ApInv.

${ }^{39}$ va[1]: corregeixo. En l'edició emprada es llegeix "va".
} 
Car aquest món és axí com hun camp de batalla; primo, contra los dimonis, que un hom ha més de mil dimonis contra si, e no•ls vehem ab los huylls corporals, e per ço havem lo bon àngel qui.ns guarda, perquè ${ }^{40}$ ell los veu bé; aprés, la carn, lo enemich portam ab nosaltres (...) no és persona deguna que vulla governar son enemich ni dar-li provisió, mas nosaltres o havem a fer; aprés, lo món, que quan los amichs vehen una persona que vol fer penitència, ells que la·y deurien provocar, ells són aquells qui la perseguexen. (...) e per ço batallar fort contra los dimonis, estar fort contra les temptacions que donen, e contra la carn per abstinències e per humilitat, e contra lo món per misericòrdia e liberalitat, no posseir res de mal just, ne desigar riquees, sinó solament passament de vida.

El món, camp de batalla. Els dimonis, atacant l'home. L'home, col·laborant amb el seu propi enemic. Els altres, per comptes d'ajudar a fer penitència, l'entrebanquen... Tot és conflicte, tot és lluita: la descripció resumeix el que, més detalladament, hem vist adés en referir-nos a Eiximenis. Tot seguit (pp. 71-72), extreu una conclusió moral d'aquesta batalla -que és la vida-: la necessitat de mantenir-se fidels, specialment ara, per lo temps de Antechrist que s acosta (p. 71). La clau, segons fra Vicent, és que vullau confessar la fe catòlica tots jorns, a matí e vespre, e axí vos conservareu.

Ara bé, la batalla també pot ser entre Jesucrist i l'home. Així, en el sermó dedicat al tema In omnibus honorificetur Deus (S I, 111-122), se'ns descriu Jesucrist com un rei que intenta entrar en una ciutat on el rebutgen ${ }^{41}$. Aquesta ciutat és lo cors de cascú i fou vençuda el divendres sant: e quan vingué lo dia del divendres sant, ell nos guanyà en lo camp de la batalla, e lo dia de Pàscua vol entrar en la sua vila. Rebutjar-lo, tot afirmant que hom no és digne d'acollir-lo, és pretextar una falsa humilitat e per ço serà dapnat. Quan el predicador explica quin profit obté Déu del fet de ser rebut, afirma:

No degú, mas ha'n la honor com entra en la vida que ha guanyada e comprada ab la sua preciosa sanch, que quant hun senyor ha batallat hun mes per pendre una vila, quan la té gran honor li és quan hi entra. Sus axí ha fet Jesucrist que·ns ha guanyat; lo bacinet, la corona, los guants, la lançada del costat ${ }^{42}$.

La identificació de Jesucrist amb un cavaller guerrer és clau en tot aquest sermó. De fet, aquesta peça abunda en mostres de moral cavalleresca,

\footnotetext{
${ }^{40}$ perquè: corregeixo pel sentit. En l'edició original es llegeix "per què".

${ }^{41} \mathrm{~S}$ I, 119.

${ }^{42}$ S I pp. 119-120.
} 
encarnada per Jesucrist ${ }^{43}$. La presa d'un ciutat vençuda, identificada amb l'ésser humà, és un pretext per a descriure com Jesucrist ha d'ésser acollit com a rei victoriós. D'altra banda, l'esment ràpid de les parts d'una armadura, a la qual s'afegeix la llançada rebuda per Jesucrist en la creu, fa pensar en algun desenvolupament que no ha quedat reflectit. En qualsevol cas, però, la vinculació, mitjançant l'al·lusió a la passió, amb la creu sembla prou evident, cosa que ens permet treure a col-lació un fragment molt explícit referit a la creu en tant que instrument de salvació -i de protecció contra els dimonis-. Em refereixo al punt en què Ferrer, al·ludint a quantes taules ha parades per a nosaltres Jesucrist (S II 24), parla de la tercera taula, que és "sapiencial" (p. 29) i de les miques que cahen de aquesta mesa sapiencial (ibidem). De les quatre miques que en cauen, la segona és allò que devem demanar, idea que remet immediatament al parenostre, que expressa set peticions. En aquest context s'esmenta la necessitat de defensar-se dels dimonis i, llavors, l'orador pregunta: E ab quinya armadura?, i respon: Hoc est, signum crucis in nomine Patris et Filii et Spiritus Sancti (p. 30), alhora que remet a un altre sermó -dedicat a la creu i a la Trinitat-, que inclou una àmplia secció dedicada a la manera de senyar-se.

Efectivament, si acudim al sermó sobre el tema Nemo potest hec signa facere, que tu facis (S I pp. 227-238), dedicat a la Trinitat, hi trobarem (pp. 234-236) una llarga reflexió sobre el signe de la creu, en la qual fra Vicent ensenya a senyar-se i insisteix en la importància de fer bé el signe de la creu, descrivint-lo acuradament i descartant diverses alternatives heterodoxes. Més encara, si el signe es fa malament, per comptes de creu es fa un "rotle", que és lo senyal del dimoni (p. 235), com es pot veure en S I, p. 280, on el seguici de dimonis que acut a recollir l'ànima d'un pecador va encapçalat per $l o$ senyal de Lucifer, és a dir, lo cercle del diable ${ }^{44}$.

L'armadura, però, pot ser molt més complexa i temible, com podem veure en el sermó sobre el tema In Ierusalem potestas mea (S II, pp. 149-157), on la citada ciutat, mercès a una detallada al·legoria, és presa com la universal christiandat (p. 149), contra la qual serà demostrada la potestat divina

\footnotetext{
${ }^{43}$ Vegeu en aquest sentit Ferrer, Como una red, ed. Ysern 2015, p. 137, n. 58, on s'analitza succintament la moral cavalleresca practicada en aquest sermó.

${ }^{44}$ Aquest ensinistrament a fer bé la creu és una preocupació recurrent de Ferrer, com podem veure en S I p. 96, on, també descriu acuradament com es fa el senyal de la creu-que identifica, en sentit heràldic, amb "les armes del rei"-i, a més, explica com les presses i la despreocupació indueixen a fer-lo mal, tot afegint-hi: "axí com deurien fer la creu [es refereix als capellans, acabant la missa], fan lo rotle; axí com los deurien dar la benedicció, envien-los-ne ab maledicció Huy! huy! ¡quanta trayció, levar la bandera de Jesús e alçar la de l'enemich!". Cal dir que tant la creu com el nom de Jesús són recursos molt grats a Ferrer com a mitjans quasi màgics contra determinades desgràcies. Vegeu, sobre aquest aspecte, Ferrer, Como una red, ed. Ysern 2015, pp. $109-110$ i p. 134 , n. 47.
} 
(p. 151). Per a intentar desenvolupar aquesta idea, Ferrer recorre al punt del llibre d'Ezequiel en què es narra el càstig de la ciutat per part de sis homes armats, comandats per un que va vestit de lli $(\mathrm{Ez}, 9)$, la qual cosa li dona peu per a parlar de les dues vestidures de Jesucrist, la una blancha e prima, e aquesta durarà tant com lo món durarà, e l'altra de ferre, e aquesta té en l'altra vida (p. 153). Aquesta vestidura fort de ferre (ibidem), que es vestirà Jesucrist en tant que jutge, s'autoritza amb una citació del llibre de la Saviesa-Accipiet pro zelu illius loricam, et pro torace iustitiam. [Et accipet pro galea iudicium certum; sumet scutum inexpugnabile aequitatem. Acuet autem duram iram] in

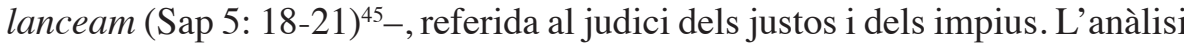
d'aquest fragment subministra a l'orador la matèria per a fer avançar el sermó: l'al·lusió al pro zelu illius s'interpreta com la gelosia que sent Jesucrist per l'ànima que el traeix i darrere la qual surt, vestit amb la lloriga (p. 153); el scutum inexpugnabile el duu a referir-se a aquests homes d'armes, qui tenen gran scut de barrera, amb els quals identifica la duresa de la sentència de Jesucrist, la qual, en l'altre món, ja no podrà ser mitigada per cap intercessió:

que quan la persona que passe de aquest món en l'altre, encara que la verge Maria e tots los sants pregassen per ella, Déus no li perdonarie, quia sumet scutum; mas no és axí en aquest món, que si és una persona en peccat mortal e ha devoció en la verge Maria o altre sant, si ella diu: "Senyor, feu-me una gràcia de tal persona que ha devoció en mi, que vós li vullau perdonar", tantost li perdone; mas en l'altre món sumet "scutum inexpugnabile"46

Recordem, però, que el text d'Ezequiel parlava de sis homes que acompanyaven el qui anava vestit de blanc. La interpretació al-legòrica no podia bandejar-los. De fet, els identifica (S II, p. 156) amb los sis órdens dels sants, dels quals fem festa, o sia: els patriarques, els profetes, els apòstols, els màrtirs, els confessors i els vèrgens e continents. Com diu Ferrer, que sien hòmens no·u cal provar, mas que sien d'armes, sí. I, amb aquesta finalitat, descriu detalladament com s'arma Jesucrist per a eixir a la batalla, en paral-lel a com ho faria un senyor terrenal en una tal situació: Senyors, quan ve en una batalla que $l$ rey se arme a exir, e los cavallers e $\cdot l s$ escuders semblantment se armen a seguir-lo, (...) axí Jesucrist se arme. E com? Llavors segueix un llarg desenvolupament en el qual, Jesucrist, com a jutge, pregunta als diversos sants tot just enumerats en relació a la salvació o condemna de les ànimes que se li

${ }^{45}$ L'orador cita segons una versió que no correspon a l'actual i que, a més, modifica a son pler. Mantenim la seva versió perquè és la base del desenvolupament posterior i completem la part omesa segons l'edició de Colunga-Turrado, inclosa a la bibliografia. El text segons la Nova Vulgata correspon a Sap 5: 17-20.

${ }^{46} \mathrm{~S}$ II, pp. 154-155. 
presenten i aquests, a tall de fiscals, acaben suggerint-li un veredicte. De fet es comporten actualitzant el context de què havien estat presos els sis cavallers que, al-legòricament, havien esdevingut representants de tots els sants: em refereixo al text d'Ezequiel vist més amunt, en el qual, el personatge que anava vestit de blanc, anava marcant amb una creu els habitants que gemegaven per les abominacions que es cometien en aquella ciutat. Els sis homes que el seguien, complint l'ordre de Déu, anaven matant tots els qui no haguessin estat marcats per la creu. Paral-lelament, ara, els sants que aconsellen Jesucrist en la seva actuació de jutge, al·ludeixen també al fet de si les ànimes presentades estan o no marcades: Portes senyal -pregunta Jesucrist a un avariciós- i aquest li respon: No. Llavors demana consell als sants i aquests conclouen: Senyor, donchs, vaje a infern (p. 157).

Si en el cas suara comentat, la ciutat ja es fa present, ni que sigui com a escenari, aquesta anirà guanyant presència per a il·lustrar la idea de l'amenaça del pecat, representada per la idea del setge. Així, en el sermó dedicat al tema Vigilate quia adversarius vester dyabolus (S II, pp. 99-103), Ferrer se centra en la necessitat de vetllar per a poder aturar l'atac del dimoni. Un dels motius que indueixen a vetllar, segons el dominic, és per temor de perill mundanal (p. 101), on es remarca ja no sols el perill del setge en si mateix, sinó amenaces que són consubstancials a aquestes situacions, com ara l'existència de possibles traïdors (pp. 101-102):

axí com, quant la ciutat se tem dels enemichs, no sabent quan vindran, què fan los de la ciutat? Vetlen, e posen guaytes per lo mur. Veus aquesta vigília no`s fa per amor de guany temporal, mas per temor de perill mundanal, majorment quan los enemichs són axí industres e forts, que subito són ací, e majorment quan en la ciutat són alguns que·ls obriran los portals, e allí ha mester major custòdia.

L'analogia, però, necessita una segona part, que desceli el sentit dels termes implicats. Aquesta clau interpretativa ens l'ofereix Ferrer tot seguit, bo i associant el castell -o vila- que vol defensar-se amb l'ésser humà, habitat per males inclinacions -les lligades al món de la carn- que, des de dins, esdevenen també amenaçadores per a la salvació final. Vegem com ho expressa fra Vicent (ibidem):

Axí Déus nos ha donada ànima en aquest castell, en aquesta vila corporal, e havem enemichs, los dimonis (multitudinem quam nemo dinumerare potest), e són axí forts, que lo menor d'ells ha poder de pendre una montanya, de lançar-la en la mar, Déu permetent, axí com si yo prenia ara una taronga la poria lançar d'ací allí. E semblantment dins en la ciutat, en nostra humanitat, havem 
enemichs, ço és males inclinacions o sentiments de la carn, per los $\cdot \mathrm{V} \cdot$ senys corporals. Donchs devem-nos avisar e vetlar.

L'al·legoria que identifica el món amb un castell -i que, per tant, concita tots els aspectes bèl-lics previsibles-, tornarem a trobar-la, en relació amb la Verge, en el sermó dedicat a l'assumpció, amb el tema Optimam partem elegit sibi Maria (S III, pp. 73-80). Ferrer comença parlant de com Jesuchrist entrà en la verge Maria, ço és lo castell, en la sua concepcióo ${ }^{47} \mathrm{i}$, tot seguit, identifica el castell amb el món, de manera semblant a com hem vist suara, i el descriu com segueix (pp. 74-75):

lo qual [es refereix al castell] ere alt per supèrbia, lo qual tenie Lucifer, e ere murat per supèrbia contra Déu, ere entorrat per avarícia, ere vallegat per luxúria e enveja, ere provehit de vitualles per gola, ere armat de armadures malicioses per peccat de ira e de accídia, que tots dormien en peccat. Aquest castell ere armat contra Déu. Vench Jesucrist a conquestar-lo, e contra aquest castell tramès los seus apòstols.

Tornem, però, al tema, esbossat més amunt, de la necessitat de vigilància. Fem-ho a través del sermó Tu vero vigila in omnibus ${ }^{48}$ (S III, pp. 89-95), centrat en la gran vigilància e diligència que devem haver envés nostre senyor Jesuchrist (p. 89). Un dels motius pel qual, segons Ferrer, cal vetllar -segons la distinctio que aplica al tema- és per temor de perill (p. 92). En la reflexió que dedica al perill, l'orador lliga de nou a la presència d'enemics, los pus forts (ibidem), especialment perillosos per tal com no ls podem veure, si bés van entorn de nosaltres per fer-nos peccar, e són molts (ibidem). Per tant, es pregunta, aprofitant de nou una metàfora militar -l'escalada de les torres- ( $\mathrm{p}$. 92) : no devem vel-lar que no siam escalats?

Què proposa fra Vicent, doncs, com a protecció contra aquests perills? Dóna una sèrie d'instruccions molt clares que, implícitament, desenvolupen la imatge al-legòrica del castell aplicant-la ara al propi cos (p. 92): Guardem la vista, que no·y pecquem; si no, lo castell se escalarà per aquest portell dels huylls -adverteix, tot recordant com s'enamorà David de la dona d'Ories en veure-li els braços nus (cf. 2 Sam 11)-; (...) guardat lo portell de les

${ }^{47}$ L'entrada en el castell simbolitza, per tant, des d'aquesta perspectiva, l'encarnació. El "castell", tanmateix, en un camp semàntic eròtic té connotacions ben diferents, com bé podem recordar amb la famosa escena entre Tirant i Carmesina en el cap. 436 de la novel·la de Joanot Martorell. Quant al castell, amb altres sentits també al·legòrics, són útils les aportacions de Salvador 1998, pp. 74-76; Rubio 1993.

${ }^{48}$ Aquest tema, que procedeix de la segona carta a Timoteu (2 Tim 4: 5), és modificat amb un afegitó: "scilicet annis, diebus, horis et momentis". 
orelles (...): fuyg a difamacions; fins i tot l'olfacte mereix ser vigilat: guayta lo odorar, no fer superfluitat per dar plaer al cors; sense oblidar tampoc la boca: parlant indiscretament, mengar e beure tempradament. Així, ràpidament, revisa los portells perillosos, los quals devem regir molt bé, però no s'està de demanar que vigilem l'altre cors, no sigui que, en quedar menys vigilat, sigui perillosament vulnerable, cosa que il-lustra amb un exemplum: uns enemics quan assetjaven un lloc, van anar a la part més accessible de la fortalesa i en distragueren els defensors enganyant-los amb unes cabres que duien les banyes amb teies enceses. Llavors aprofitaren per a escalar la part més difícil de la fortalesa, que havia quedat desprotegida ${ }^{49}$.

"Castell" i "cos" tornarem a trobar-nos-els aparionats de nou en una situació de setge que descriu Ferrer per a explicar com el dimoni pot arribar a dominar la seva víctima a través d'un triple assalt, descrit en termes militars (S III, p. 273):

Lo castell és quiscun home o dona, los quals Déus ha fets e formats, e són seus. Mas, què fa lo dyable? Escala'l ab tres escales. La primera és la ymaginació del peccat. Encara no és pres lo castell, que no és peccat per ymaginar e pensar. E depuix el mesquí de guardià, ço és, l'enteniment, pren altra escala. E quinya? La delectació de la cosa: e encara no és pres lo castell. Mas la III ${ }^{\mathrm{a}}$, que finalment l'om o dona consent en lo peccat que's face, encara que no es face, ja és pres lo castell, que aquell consentiment de del-liberada voluntat és peccat mortal. E veus en quinya manera lo dyable pren senyoria sobre hòmens e dones.

Ferrer arrodoneix la descripció de l'estratègia del diable amb una conclusió important (ibidem): Veus quinya senyoria ha lo diable: per tirannia, per furt. I és que, en realitat, oposa la senyoria natural de Déu a la tirànica del dimoni. Si no fos per la seva capacitat d'enganyar, de conquerir fraudulentament no ha senyoria sobre una formiga ne sobre un gra de mostaya.

Atès el caire del tema que resseguim en aquest estudi, potser no resultarà sorprenent que Jesucrist i Llucifer arribin a encontrar-se en camp clos, com a vertaders cavallers. Ens ho explica Ferrer en el sermó del primer diumenge de quaresma, dedicat al tema Ecce angeli accesserunt, et ministrabant

\footnotetext{
${ }^{49}$ Els defensors del lloc s'embadoquen contemplant l'espectacle de les cabres flamígeres, discutint si són ànimes. Tot seguit, Ferrer introdueix diverses mostres de derrotes que es poden produir per concentrar-se només en els "portells importants", que citava adés. Entre elles destaca l'únic esment directe, si no vaig errat, en els seus sermons de la pederàstia (S III, p. 93): “'Yo me guardaré de luxúria, vull viure cast'. Ve lo dimoni e tempte; e com lo prevere tendrà a serví seu hun fadrí, e per guardar-se de dona, use lo fadrí. Aquest castell serà pres per la part pus fort, que cau en lo peccat pus greu, que és contra natura. També alguns se volen guardar de dones e pecquen contra natura, en si matexs, ab bèsties o en altra manera". La cursiva és meva.
} 
ei (Q I, 87-94), centrat en el dejuni de Jesucrist, durant quaranta dies, en el desert. El dominic explica, per a acabar el sermó, quin fou lo fruit provenient (p. 94) obtingut amb el llarg dejuni de Jesús i, per a fer-ho de la manera més clara possible, recorre a la imatge de dos cavallers entrant en lliça (ibidem):

Quan dos cavallers deuen batallar en un camp clos, alt en un cadafal està lo rei, que assegura lo camp; los amics dels primers batallants estan en part, e quan lo u és vençut, fuig ab sos amics e parents, e al que venç, los amics se acosten ab les trompetes sonants.

Vegem ara, però, el combat en versió al·legòrica, amb uns participants que, encara que actuïn segons l'esquema descrit, són del tot peculiars. D'entrada, els grans prínceps implicats són Jesucrist, príncep de santedat, $e$ Llucifer, príncep de pecat. D'altra banda, el rei que assegura el camp és Déu lo pare i el públic, com és esperable, es divideix entre los àngels de una part e los diables de l'altra part. I aleshores, el predicador entra a descriure l'acció (ibidem):

Les armes de Llucifer, llança, espasa e darga, e ab aquelles armes havia vençut tants. Lo diable era lo temptador. Començà-li a llançar la llança, pecat de gola; e puis, ab l'espasa de vanaglòria, l'espà se trencà, e ab la daga de avarícia volc-lo ferir. E Jesucrist li féu caure la daga, e lo diable Llucifer fuig. ¡Oh si els haguésseu oïts los àngels, dients ab gran alegria: "Viva, viva lo fill de la Verge Maria!"

Vet ací com cada arma està especialitzada en un pecat concret, però una a una són derrotades. A la fi, els àngels transmetran a la Verge la victòria de son fill. I no sols. També l'assabentaran que havia fam, per la qual cosa ella li farà arribar, mitjançant els àngels, uns pocs de brots, e sardina e vi. Després, els mateixos àngels li retornaren les sobralles $e$, llavors, la beneita menjà e se dinà.

\section{UN SERMÓ DE QUARESMA TOTALITZADOR}

Per a anar acabant aquest estudi, potser val la pena deixar de banda les citacions fragmentàries i presentar un text sencer, on un bon ventall de desenvolupaments semblants als vistos fins ara es conjuntin i s'harmonitzin. En les següents ratlles acudirem al sermó de quaresma dedicat al tema Fortis armatus custodit atrium suum (Q I, pp. 179-185) ${ }^{50}$.

${ }^{50}$ N'existeix una altra versió en S V, pp. 203-207, que tindré en compte subsidiàriament. Tots dos sermons han estat tractats, des d'una altra perspectiva, en Ysern 2017, pp. 39-43 i 
L'esmentat sermó s'inicia declarant que la seva matèria serà la batalla campal e general que en aquest temps de quaresma ha lo poble cristià contra los dimonis (p. 179). Heus ací la paraula clau: "batalla". Encara esdevé més explícit només començar el desenvolupament que haurà de justificar l'estructura del sermó. Vegem-ho (ibidem):

\begin{abstract}
Vosaltres devets pensar que, en temps de quaresma, és així com un camp de batalla, en la qual tot lo poble cristià fa batalla general contra los dimonis, car, en altre temps de l'any, bé són molts devots que tostemps estan en batalla contra los dimonis, e pecats e temptacions; mas aquelles són persones poques. Emperò, ara, en quaresma, és la batalla de tot lo poble cristià contra los dimonis. Per ço diu: "Confortamini in Domino, et induite armaturam Dei" (Ef 6, 10-11). Los enemics de natura humana no us esglaen: siam confortats en la potència de la virtut de Déu, e vistam-nos la sua armadura. ¿Quina és? Penitència bona e devota.
\end{abstract}

La batalla, ara, en quaresma, és general i implica més participants -tot el poble, de fet-. I, per a encoratjar, enmig d'una situació tan amenaçadora, Ferrer fa servir una citació que ja ens resulta ben familiar: la de la carta de Pau als efesis ${ }^{51}$, associada, en aquest cas, a la penitència, sagrament que esdevé columna vertebral de tot el desplegament retòric subsegüent, car les "tres armadures" de què arma l'església els cristians hi tenen a veure (p. 179): la primera és un escut per a defensar lo cos que es fa correspondre al dejuni, per tal com aquest toca tot lo cos per l'aflicció corporal. La segona "armadura" és la "cervellera", és a dir, el casc, associat a l'oració; la tercera, la llança, car la confessió és llançada que dóna al diable. En suma, Lo poble cristià, armat de la fe catòlica en les dites maneres, porà entrar en batalla contra lo diable. Vegem, però, com és aquesta batalla.

Ferrer opta per explicar el desenvolupament d'aquesta batalla tot recorrent, com a punt de comparació, a un referent -l'exèrcit reial- més pròxim i familiar al seu destinatari, la qual cosa fa que distingeixi set grups diferents de soldats -set diferències de gents (Q I, p. 180)-: algarers o ginetaris (ibidem), ballesters (p. 181), nafils (p. 182), penoners (p. 182), hòmens de cavall

s'inclouen en ApInv, núm. 354, pp. 605-606, on es cataloguen també algunes versions llatines. Vegeu, a més, SP, núm. 113, per a la fitxa amb l'esquema corresponent a aquest tema. De la versió de Q n'hi ha traducció castellana, que cito per l'interès dels comentaris que l'acompanyen, en Ferrer, Como una red, ed. Ysern 2015, pp. 252-264.

${ }^{51} \mathrm{Cal}$ dir que és una citació modificada -abreujada-. Vet ací l'original: "De cetero confortamini in Domino et in potentia virtutis eius. Induite armaturam Dei, ut possitis stare adversus insidias Diaboli". 
(p. 183), peons (p. 184), rècues o atzembles (p. 185) ${ }^{52}$. Com és d'esperar, aquesta detallada classificació esdevé l'esquelet del sermó, que consisteix a omplir de contingut, a desenvolupar cadascuna d'aquestes seccions, és a dir, a definir les funcions i característiques dels diversos "soldats" -si continuem amb la metàfora bèl-lica que ens proposa l'orador- que les integren.

Si comencem amb els "algarers", aquests són ginetaris per descobrir los aguaits dels enemics, e aquells són llaugers, quasi volants, van guardants deçà e dellà (Q I, p. 180). Es tracta, doncs, d'un "cos militar" especialitzat a detectar les possibles emboscades dels enemics. En aquesta versió al·legòrica de l'exèrcit, aquesta secció la componen persones contemplatives que ab lo ginet van quasi volant e corrent per muntanyes, descobrint los aguaits dels diables. És precisament la idea d'“ascensió", derivada del fet d'anar per les muntanyes, la base de comparació que permet associar els "algarers" amb els "contemplatius", per tal com allà se'n pugen aquests, a la muntanya del cel contemplant en les penes de l'infern o en les prosperitats d'est món, que no és sinó fum, tot pensant en quines maneres tenen los dimonis a temptar e a fer caure en diverses maneres de pecats. Aquesta "mobilitat espiritual" fa que fra Vicent encoratgi a pelegrinar sempre per l'esperit, contemplant (p. 181), evitant així els romiatges, sempre considerats perillosos ${ }^{53}$.

El grup dels ballesters (p. 181) també es presta a una interpretació al-legòrica interessant a partir de l'arma que usen: la ballesta. Integren aquest grup les persones "actives", "misericordioses", ja que Cada almoina e cada obra de misericòrdia és virató que fer al diable. La vinculació de la ballesta amb l'almoina dona peu a una al·legoria segons la qual l'“arbrer dret" equival

${ }^{52}$ En tota aquesta descripció del cos militar que ha de combatre les tropes de l'ordre dels dimonis, fra Vicent no fa més que seguir fidelment allò fixat en SP núm. 113,p. 192: "Nota ergo in exercitu christiano, nunc fortiter armato contra demones, differentias pugnatorum 7 , ad modum regii exercitus". Les divisions que estableix en el conjunt de l'exèrcit són (ibidem): "Cursarii explorantes; Ballistarii sagitantes; Tubicinarii proclamantes; Vexillarii designantes; Equitarii penetrantes; Peditarii concertantes; Saumatarii comportantes". Entre la versió proporcionada per $\mathrm{Q}$ i per $\mathrm{S}$ hi ha diferències quant a la denominació dels diversos grups -no pas quant a la interpretació que se'n fa-, com posa de relleu Ysern 2017, pp. 41-42.

${ }^{53}$ De fet, en la versió editada en $\mathrm{S}$ s'hi fa un esment molt més concís d'aquestes consideracions, alhora que es remet al sermó de l'assumpció, on, efectivament, es desenvolupa aquesta idea gràcies a la vida de Maria Magdalena, de la vocació contemplativa de la qual s'extreu la següent interpretació moral (S III, 126): "que vosaltres vullau anar visitar los santuaris no corporalment, mas spiritualment, axí com ella. (...) a Jerusalem vés en spirit, dient: En tal loch mon senyor Jesuchrist fo pres, lligat, etc., e en tal loch açotat, axí e axí, per mi pecador ". El perill que tenia in mente el dominic és declarat en l'exemplum que clou aquesta reflexió moral (p. 127), en la qual un predicador narra que s'havia hostatjat en un lloc on, el dia abans, havien dormit plegats, tots "de rebolta", "molts pelegrins, hòmens e dones". Sobre aquesta idea ja havia insistit en S III, p. 79, començant amb una afirmació molt contundent- "quan anaren a Roma l'altre any, moltes dones hi anaren prou fembres que tornaren putanes" -i acabant amb un altre exemple, molt semblant al suara vist, però aquesta volta basat en la seva pròpia experiència. 
a la "intenció dreta" i l'arc, que és tort, és lo cos, que es deu inclinar a haver compassió de son proïsme. La corda tibant hi representa el manament de Déu. Aquests tres elements permeten llançar el virató, el qual darà gran colp al diable $^{54}$. Cal dir que l'almoina concita l'interès de fra Vicent molt sovint $\mathrm{i}$ adesiara s'hi atura per tal d'explicar quina almoina és admissible, quines són les característiques de la bona almoina i quina no serveix de res -com ara la que es fa amb diners d'usura $-{ }^{55}$.

Quan la batalla comença, és important que hi hagi trompetes en llocs alts que serveixin, sonant, perquè els soldats mantinguin llur valor, car Lo crit de la trompeta mou tots los coratges, e mou la sang (p. 182) i, de fet, segons llegim en la versió S V, p. 205, ans que no toquen, los cavallers estan segurs, e quan aquells toquen, llavors comencen a batallar. En l'exèrcit al-legòric que ens descriu Ferrer, els trompetes són Los prë̈cadors ab llur preïcació de trompa (Q I, p. 182), afirma en al·lusió a la complexitat estructural de l'instrument, parangonable a la predicació, que també és molt complexa $(\text { ibidem })^{56}$ :

no és feta [enteneu: la predicació] axí com a canya, mas podeula plegar; e veus ací preïcació que no deu ésser en una part, mas certes partides que lliguen unes ab altres, axí com la trompeta met un canó dins altre.

De més a més, ultra aquesta semblança formal, Ferrer en remarca una altra, de caire més aviat ètic, ja que la trompa és estreta a la boca e al cap ampla (ibidem), com és la vida del bon predicador, el qual hauria d'estrènyerse en son estudi. La part ampla de la trompeta, però, al-ludeix a la comunicació del missatge (ibidem): E puis eixampla's quan ho diu a vosaltres. D'altra banda, al tocar de la trompa, les mans hi haveu a tenir, cosa que vol dir que el predicador ha de viure en consonància amb allò que predica: lo que preïca, que hu faça per obra (ibidem).

D'aquesta manera, successivament, l'orador descriu les funcions dels batallons de què es compon l'exèrcit que ha d'enfrontar-se al del dimoni,

\footnotetext{
${ }^{54}$ Q I, p. 181. La versió que ens n'ofereix S V, p. 205, curiosament, bandeja l'arbrer i atribueix la seva qualitat a la corda: "Secundo, la corda està dreta, ço és que la faces per honor de Déu, no per vanitat". No es tracta d'un error ni d'un oblit, ja que, més avall, continua traient significat d'aquesta associació, com veiem amb la següent similitudo (ibidem): "tant com la corda se encorne, tant fa lo colp pus fort; axí de l'almoyna, tant com se done ab major compassió tant fir lo diable".

${ }^{55} C f$., com a síntesi útil, Ferrer, Como una red, ed. Ysern 2015, p. 282, "Limosna".

${ }^{56}$ No és estrany que Ferrer reflexioni sobre el sermó des d'un punt de vista retòric, estructural. És ben coneguda la seva definició del sermó com a xarxa (S II, pp. 46-47). Vegeu-ne més definicions en Ferrer, Como una red, ed. Ysern 2015, pp. 76-78.
} 
en el qual també compten els penitents, que són els portadors de banderes -els penoners- (Q I, pp. 182-183) o els "hòmens a cavall" (pp. 183-184), que són les persones verges ${ }^{57}-\mathrm{i}$ que cal no confondre amb els peons, hòmens $e$ dones continents, que no són vèrgens, que són en matrimoni (p. 184)- o los qui han cura de ànimes, prelats, rectors, vicaris, representats per les rues o atzembles, que porten armadures, e vitualla, e medecines (p. 184). Aquests darrers socorren els caiguts fornint-los d'allò necessari per continuar endavant: la nafra causada pel pecat de supèrbia, la guareixen amb estopada de humilitat; la de luxúria, amb vi i oli, amb penitència e almoines; i qui es queda sense forces, en rep gràcies a menjar aquelle hòstia sagrada (ibidem).

\section{UN PUNT DE CONTRAST: LA BATALLA PARÒDICA}

Quina batalla tan diferent la que suara hem analitzat de la del Libro de buen amor (LBA, est. 1067-1209), la pelea que ovo don Carnal con la Quaresma $^{58}$, la qual inevitablement se'ns fa present, com a contra-imatge, tot llegint el sermó vicentí. D'alguna manera, l'obra de Juan Ruiz conjumina tots el elements que hem vist fins ara: el tema carnavalesc - evocat, ja l'entrada d'aquest estudi, pel quadre de Pieter Brueghel, el vell-,reflectit a través de la contesa entre "don Carnal" i "doña Cuaresma", i l'al-legoria de les armes del cristià ${ }^{59}$.

La batalla descrita per l'Arxiprest és una contesa al-legòrica i, alhora, paròdica que expressa literàriament la mateixa realitat del sermó sobre el tema Fortis armatus custodit atrium suum (Q I, pp. 179-185) -la coexistència problemàtica del món de la carn i el de l'esperit-, com bé expliquen Zahareas i Pereira en llur edició del $L B A$ (p. 979):

${ }^{57}$ Aquesta associació es justifica perquè aquestes persones "se són sabudes regir sobre lo cavall, que no són caiguts en lo fang de luxúria" (Q I, p. 183). De fet, fra Vicent explica: "Lo cos és cavall, l'esperit és lo cavaller. [...] Axí com cavaller ha mester bon fre a la boca del cavall, així lo teu fre sia abstinència de menjar e beure; si no, no el poreu tenir e gitar-vos ha en lo fang de luxúria: així tingats bon fre" (ibidem). Evidentment, aquestes consideracions serveixen per a perfilar el sentit de la imatge del cavaller adormit sobre la seva cavalcadura, que trobem, per exemple, en el Llibre de l'orde de cavalleria lul-lià, d'on passa al Tirant lo Blanch, a través del Guillem de Varoic (vegeu el comentari d'Albert Soler en la seva edició de Ramon Llull, 1988, pp. 66-68, i Ferrer, Como una red, ed. Ysern 2015, p. 261, n. 662).

${ }^{58}$ Tornem ací sobre algunes de les referències resumides en Ferrer, Como una red, ed. Ysern 2015 , p. 252, n. 623. Com és habitual amb el $L B A$, els números es refereixen a les diverses estrofes i, el versos, són indicats per lletres. Convé tenir presents les interessants glosses dels editors a aquest famós encontre ( $L B A$, pp. 979-1023).

${ }^{59}$ L'Arxiprest hi dedica les estrofes 1579-1605 (amb glosses dels editors en les pp. 11351148), sobre les quals veg. també Lecoy 1938, pp. 179-187; Ricard 1973 i Sánchez 1998. 
La pelea es una alegoría de la polarización de lo mundano (loco amor) y lo espiritual (buen amor). (...) Juan Ruiz mezcla el género de la "pelea alegórica" entre la carnalidad y la abstinencia y la "épica burlesca" en que se imitan, en un contexto carnavalesco, varias fórmulas de la juglaría épica, como por ejemplo los temas de las "hazañas", los "desafíos", las "venganzas", "las mesnadas", los "triunfos", etcétera.

En l'obra de Juan Ruiz, però, el triomf comença essent de Quaresma (est. 1127ab): Mandó a don Carnal que guardase el ayuno / e que lo toviesen ençerrado a do non lo vea ninguno; però, a l'últim, la victòria és de don Carnal, que obliga Quaresma a fer-se fonedissa (est. 1203-1209), després que aquesta s'adona que no compta ja amb cap auxili. La seva fugida permet l'arribada de dos enperadores (est. 1210d), Amor i Carnal, que són rebuts enmig de gran festa. En l'endemig d'aquests dos punts hi ha hagut la gran batalla ja al·ludida, en la qual s'han enfrontat les tropes dels dos capitosts, que són descrites acuradament. Carnal Puso en la delantera muchos buenos peones / gallinas e perdizes, conejos e capones, (...), seguits de ballesters, que són las ánsares, çeçinas, costados de carneros, / piernas de puerco fresco, los jamones enteros (est. 1084bc). No hi poden faltar, en altres posicions, muchos buenos faisanes, los loçanos pavones (est. 1086b), ni senglars o daines. Per contra, les forces de Quaresma són descrites sobre la marxa, segons van entrant en acció. Ara Carnal és atacat per un puerro cuellealvo (est. 1102b), de seguida ajudat per la salada sardina, que fereix muy reziamente una gallina (est. 1103). De mica en mica hi van apareixent altres animals, majorment de procedència marina, que també fan el seu fet contra Carnal ${ }^{60}$.

La perspectiva de la batalla en el text vicentí és diferent. Primer que res, la seva al·legoria no és paròdica. No pretén cap mena de burla o sarcasme. És una al·legoria que prova de fer entenedora una ensenyança seriosa, a la qual se subordina com a vehicle expressiu. No descriu la victòria, que es desitja i es persegueix, ans només el procés, és a dir, la batalla. Amb la finalitat d'aconseguir la victòria, l'orador proposa, al seu sermó, una manera de lluitar, dissenya un exèrcit.

\footnotetext{
${ }^{60} \mathrm{El}$ caràcter joiós, burlesc i grotesc de l'Arxiprest sembla refrenar-se, tanmateix, en tractar el tema de les armes del cristià. Recordem, però, que la duplicitat de tons -burlesc/seriós- és un dels trets més definidors de la magna obra de Juan Ruiz, la qual cosa, també en l'aspecte tractat ací, ha provocat interpretacions molt diverses. Veg. els comentaris dels editors del $L B A$, pp. 1137-1138.
} 


\section{FINAL}

Comptat i debatut, al llarg d'aquestes poques pàgines hem pogut comprovar la ductilitat del mecanisme constructiu que representa l'al·legoria, especialment aplicada sobre un topos tan ric i potent semànticament. L'armadura, d'arrel paulina, i la descripció de la vida en termes bèllics han estat els elements que hem estudiat ací, fonamentalment, en el context de la predicació de Vicent Ferrer, encara que amb al-lusions a altres autors també.

Evidentment, el camp no ha quedat exhaurit, car és palès que les armes i la batalla constitueixen motius de gran rendibilitat, que serveixen per a expressar lliçons i plantejaments tan diferents com els que podem representar per l'oposició entre el dominic Vicent Ferrer i l'arxiprest Juan Ruiz -i encara hauríem pogut acréixer fàcilment la documentació literària si haguéssim recorregut, per posar-ne només un parell d'exemples, al Llibre de l'orde de cavalleria de Ramon Llull o a l'Arnès del cavaller de Pere March-. De fet, sembla que la cosa continua: en una de les recerques que he fet per internet en relació al present treball, m'ha sorprès trobar algú que descrivia l'espasa del cavaller cristià com una espasa tipus làser, i, d'ací en avant, tot s'omplia de referències a la famosa pel-lícula Star Wars. Al cap i a la fi, les al·legories no coneixen més límits que els de la imaginació de qui les fa servir.

\section{BIBLIOGRAFIA CITADA}

\section{FONTS}

Eiximenis, Francesc, Lo crestià, antologia a cura d'Albert Hauf, (Les millors obres de la literatura catalana; 98), Barcelona, Edicions 62 - La Caixa, 1983.

Ferrer, Vicent, Sermons, ed. Josep Sanchis Sivera, Gret Schib, 6 vols., Barcelona, Barcino, 1932-1988.

Ferrer, Vicent, Sermons de quaresma, ed. Manuel Sanchis Guarner, 2 vols., València, Clàssics Albatros, 1973.

Ferrer, Vicent, Sermonario de Perugia (Convento dei Dominicani, ms. 477),

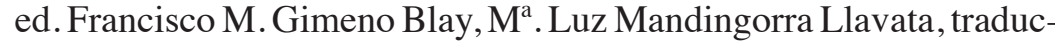
ción al castellano de Daniel Gozalbo Gimeno, amb la col·laboració de Rebeca Sánchez Moreno, València, Ajuntament, 2006.

Ferrer, Vicent, Como una red. Sermones de Vicent Ferrer, ed. i trad. al castellà Josep Ysern, València, Publicacions Universitat de València, 2015.

Haymo, Enarratio in divi Pauli Epistolas en Opera omnia, vol. II, ed. Jacques Paul Migne, Patrologia latina, vol. 117, 1881. 
Llull, Ramon, Llibre de l'orde de cavalleria, ed. Albert Soler, Barcelona, Barcino, 1988.

March, Pere, Obra completa, ed. Lluís Cabré, Barcelona, Barcino, 1993.

Maurus, Rabanus, Enarrationum in epistolas beati Pauli. Liber nonus, en Opera omnia, vol. 6, ed. Jacques Paul Migne (Patrologia latina; 112), 1852

Ruiz, Juan, Libro del Arcipreste (Libro de buen amor), ed. Anthony N. Zahareas, Óscar Pereira Zazo, Madrid, Akal, 2009.

Strabo, Walafridus, Glossa ordinaria, ed. Jacques Paul Migne (Patrologia latina; 113-114), 1852.

\section{ESTUDIS}

Associació Bíblica de Catalunya (ed.) (1994), La bíblia, trad. catalana interconfessional, Barcelona, Editorial Claret - Societat Bíbliques Unides.

Colunga, Albertus; Turrado, Laurentius (eds.) (1985), Biblia vulgata, Madrid, Biblioteca de Autores Cristianos.

Glossa ordinaria: https://big.hypotheses.org/glossa-ordinaria [consulta: $15 / 12 / 2017]$.

Hauf, Albert (1990), La Quarentena de contemplació de fra Joan Eiximeno en: D’Eiximenis a Sor Isabel de Villena. Aportació a l'estudi de la nostra cultura medieval, València, Universitat - Biblioteca Sanchis Guarner, pp. 219-300.

Lausberg, Heinrich (1966-1969), Manual de retórica literaria. Fundamentos de una ciencia de la literatura, trad. al castellà de José Pérez Riesco, 3 vols., Madrid, Gredos.

Lecoy de la Marche, Felix (1938), Recherches sur le Libro de Buen Amor de Juan Ruiz, Archiprêtre de Hita, París, Droz.

Nova Vulgata. Bibliorum sacrarum editio sacrosancti oecumenici concilii Vaticani II: http://www.vatican.va/archive/bible/nova_vulgata/documents/nova-vulgata_index_lt.html [consulta: 15/12/2017]

Perarnau, Josep (1999), Aportació a un inventari de sermons de sant Vicenç Ferrer: temes bíblics, títols i divisions esquemàtiques, "Arxiu de textos catalans antics" 18, pp. 479-811.

Ricard, Robert (1973), Las armas del cristiano en el Libro de buen amor, en Criado de Val, Manuel (ed.), El Arcipreste de Hita: el libro, el autor, la tierra, la época. Actas del Primer Congreso Internacional sobre el Arcipreste de Hita, Barcelona, SERESA.

Rubio Tovar, Joaquín (1993), El castillo en la literatura, en Cámara, Alicia (ed.), Castillos, fortificaciones y recintos amurallados en la 
Comunidad de Madrid, Madrid, Consejería de Educación y Cultura, pp. 57-65.

Salvador Miguel, Nicasio (1998), Castillos y literatura medieval, "Medievalismo. Boletín de la Sociedad Española de Estudios Medievales" 8, pp. 65-78.

Sánchez Herrero, José (1998), El catecismo del Libro de buen amor del Arcipreste de Hita, "Historia, Instituciones, Documentos" 25, pp. 611-624.

Soukup, Pavel (2007), Metaphors of the Spiritual Struggle Early in the Bohemian Reformation: The Exegesis of Arma Spiritualia in Hus, Jakoubek, and Chelcický, "The Bohemian Reformation and Religious Practice" 6, pp. 87-109 (ed. de Zdeněk V. David and David R. Holeton, Praga, Academy of Sciences of the Czech Republic, Main Library) http://www.brrp.org/proceedings/brrp6/soukup.pdf [consulta: $15 / 12 / 2017]$

Wang, Andreas (1975), Der "miles christianus" im 16. und 17. Jahrhundert und seine mittelalterliche Tradition, Berna - Frankfurt del Main, Lang.

Ysern, Josep A. (2017), A propòsit dels nusos mòbils en la construcció dels sermons vicentins, "Revista de filología románica" 34/1, pp. 33-62. http://dx.doi.org/10.5209/RFRM.55628 [consulta: 15/12/ 2017].

Fecha de recepción del artículo: abril 2018

Fecha de aceptación y versión final: noviembre 2018 